\title{
Controls on the recent speed-up of Jakobshavn Isbræ, West Greenland
}

\author{
C.J. VAN DER VEEN, ${ }^{1,2}$ J.C. PLUMMER, ${ }^{1,2}$ L.A. STEARNS ${ }^{1,3}$ \\ ${ }^{1}$ Center for Remote Sensing of Ice Sheets, University of Kansas, 2335 Irving Hill Road, \\ Lawrence, Kansas 66045-7612, USA \\ E-mail: cjvdv@ku.edu \\ ${ }^{2}$ Department of Geography, University of Kansas, 1475 Jayhawk Blvd, Lawrence, Kansas 66045-7613, USA \\ ${ }^{3}$ Department of Geology, University of Kansas, 1475 Jayhawk Blvd, Lawrence, Kansas 66045-7613, USA
}

\begin{abstract}
Jakobshavn Isbræ, West Greenland, underwent a large, rapid and not well understood change in flow dynamics in 1998, leading to a doubling of its ice discharge rates. We calculate the width-averaged forces controlling flow of Jakobshavn Isbræ in 1995, 2000 and 2005 to elucidate processes responsible for this change in flow speed. In contrast to earlier suggestions, we conclude that the observed acceleration was not caused by the loss of back-stress due to weakening and subsequent break-up of the floating ice tongue alone. Gradients in longitudinal stress are small at all times considered ( $\sim 3 \%$ of the driving stress) and basal and lateral drag provide resistance to flow. Over the 10 year period considered, the average driving stress increased by $20 \mathrm{kPa}$, which was balanced by a comparable increase in lateral drag. We surmise that the velocity changes resulted from weakening of the ice in the lateral shear margins and perhaps a change in properties at the bed. Possible mechanisms for weakening of ice in the lateral shear margins include cryo-hydrologic warming of subsurface ice in the ablation zone and hydraulic weakening due to higher water content of ice in the shear margins.
\end{abstract}

\section{INTRODUCTION}

Recent studies show that the contribution of the Greenland ice sheet to sea level has greatly increased in the past decade (e.g. Luthcke and others, 2006; Rignot and others, 2008; Velicogna, 2009). The increase in mass loss is from increased discharge of fast-moving outlet glaciers (e.g. Rignot and Kanagaratnam, 2006; Rignot and others, 2008) and enhanced ablation and runoff (Van den Broeke and others, 2009). Increased discharge through outlet glaciers usually coincides with large thinning rates, accelerating ice flow and retreat of the terminus. Howat and others (2008) observed synchronous retreat and acceleration of 32 calving glaciers along the southeastern coast of Greenland between 2000 and 2006. Moon and Joughin (2008) examined ice-front changes of 203 glaciers, including tidewater glaciers with grounded calving fronts, non-marine land-terminating glaciers, and glaciers with floating ice tongues, and found an increase in the retreat rate of tidewater glaciers over the period 2000-06 compared with the previous 8 year period, 1992-2000. Glaciers terminating on land exhibited little change over the time period considered, while glaciers with floating ice tongues showed large individual changes associated with episodic calving events, but no obvious coherent trend. These and many other observations have raised the concern that in the foreseeable future the contribution of the Greenland ice sheet to global sea level may be substantially greater than predicted by ice-sheet models that do not incorporate the physics of rapidly changing outlet glaciers (e.g. Solomon and others, 2007). Gaining a better understanding of the mechanisms involved in the speed-up of Greenland outlet glaciers is therefore imperative to better constrain predictions of future sea-level rise.

Our objective is to study changes in flow dynamics of one Greenland outlet glacier, Jakobshavn Isbræ, West Greenland. At the turn of the millennium, this glacier underwent large changes after almost half a century of relative stability
(Csatho and others, 2008). Over the period 1997-2001, the lower reaches of Jakobshavn Isbræ thinned by more than $40 \mathrm{~m}$ (Krabill and others, 2004; Thomas, 2004) after several years of thickening (Thomas and others, 1998). Airborne laser altimetry surveys conducted in 2002 and 2003 showed thinning rates in excess of $10 \mathrm{~m} \mathrm{a}^{-1}$ over much of the lower trunk (Thomas, 2004). Speeds near the terminus increased from $\sim 6 \mathrm{~km} \mathrm{a}^{-1}$ in 1995 to $>12 \mathrm{~km} \mathrm{a}^{-1}$ in 2005 , speeds that are sustained today (Joughin and others, 2004, 2008a). Coincident with the initial acceleration, the peripheral floating ice tongue weakened and collapsed (Joughin and others, 2004), perhaps as a result of above-normal summer melting in 1997 (Thomas, 2004) or an intrusion of warm ocean water into the fjord (Holland and others, 2008).

The behavior of Jakobshavn appears to validate early theories of marine-based glacier stability (Weertman, 1974; Thomas, 1979; Hughes, 1986): the loss of resistive buttressing from the disintegration of the ice tongue causes nearinstantaneous velocity and thickness changes. This loss of resistive buttressing at the front causes an increase in extending flow that theoretically can trigger a series of positive feedbacks that propagate upstream, resulting in an increase in ice-stream velocity along the entire trunk (i.e. the 'Jakobshavn effect'; Hughes, 1986). Following this hypothesis, Howat and others $(2005,2008)$ argue that the observed speed-up of Greenland outlet glaciers can be explained by the loss of resistive stress at the glacier front which resulted in an increase in the average effective driving stress and hence ice speed.

An alternative hypothesis, proposed by Thomas (2004), suggests that changes in ice flow may have been triggered by a comparatively small perturbation at the ice front associated with calving, but that, without some additional mechanism, ice velocities and thinning rates should start to decrease after several years. Proposed feedback mechanisms include weakening of the marginal ice due to softening 
induced by heat production and/or fabric development in the zone of intense lateral shear, or increased basal lubrication from meltwater input to the glacier bed. Pfeffer (2007) proposed a model for glacier instability where thinning leads to a decrease in effective basal pressure, and thus an increase in the sliding velocity. On the other hand, Truffer and Echelmeyer (2003) argued that the dynamics of Jakobshavn do not offer any mechanism that would make the glacier unstable. They successfully modeled observed velocities assuming the local driving stress is balanced by lateral drag and basal drag. Because the position of the lateral shear margins is controlled by bedrock topography, these authors concluded that speed-up resulting from migrating shear margins is not likely to happen and that changes in flow speed should therefore be expected to occur on longer timescales (on the order of centuries or more).

Until now, none of the hypotheses summarized above has been subjected to a rigorous analysis using measured velocities to evaluate the location and magnitude of stress resisting flow and how these stresses changed during the speed-up. This study aims to conduct such an analysis for Jakobshavn Isbræ. Each hypothesis assigns different roles to resistive stresses opposing the gravitational driving stress. Thus, by considering partitioning of flow resistance during the speed-up, it might be possible to accept or reject individual hypotheses. In particular, evaluation of longitudinal stress gradients over time can test the hypothesis that observed changes were initiated at the glacier terminus and propagated up-glacier through the transmission of longitudinal stress gradients.

A quantitative evaluation of forces acting on Jakobshavn Isbræ has hitherto been hampered by a lack of knowledge of the geometry of the bed. Advances in airborne radar sounding have resulted in detailed mapping of the deep and narrow channel through which the glacier moves and the production of a regional bed map (Plummer and others, 2008). These bed elevation data together with measurements of surface speed and surface elevation are combined to evaluate changes in forces acting on the glacier for the years 1995, 2000 and 2005. Again, our objective is to investigate possible causes for the onset of rapid thinning and acceleration of Greenland's largest and fastest-moving outlet glacier.

\section{DATA AND METHODS}

Determination of forces relies on measurements of ice thickness, surface slope and ice velocity. Here we use a combination of previously published velocity maps (Joughin and others, 2004, 2008a) and ice geometry derived from airborne radar sounding and laser altimetry to investigate resistive stresses at three times: 1995, 2000 and 2005.

\subsection{Ice thickness and surface elevation}

Since 1993, the University of Kansas has collected icethickness measurements over the Greenland ice sheet using airborne radar (Gogineni and others, 1998) operating concurrently with the NASA Airborne Topographic Mapper (ATM) lidar instrument. The radar is capable of sounding ice $3 \mathrm{~km}$ thick with a range resolution of $4.5 \mathrm{~m}$ (Gogineni and others, 2001) while the lidar sensors resolve surface elevations to an accuracy of $10 \mathrm{~cm}$ (Krabill and others, 1995). Co-registering the radar and laser data and subtracting the radar ice thickness from the laser surface elevation provides the elevation of the bed at each sounding location.
Because of its significance in ice-sheet drainage and potential contribution to sea-level rise, considerable attention has been given to Jakobshavn Isbræ with respect to the spatial distribution of radar surveys. The high density of radar flight-lines allowed point measurements to be interpolated to a $750 \mathrm{~m}$ grid using the ordinary kriging method (Plummer and others, 2008). This bed topography map is used here.

Driving-stress estimates require accurate surface elevations, which are derived from airborne lidar sounding. A relatively high density of laser flights over Jakobshavn in 1997 and 2005 allowed for a detailed description of surface elevation in the lower channel in these two years. Ordinary kriging was used to create a continuous surface digital elevation model (DEM) for both years, with error estimates $\sigma \leq 20 \mathrm{~m}$ for 1997 and $\sigma \leq 5 \mathrm{~m}$ for 2005. These surface elevations are used to calculate values of driving stress in both years.

Ice-thickness data are needed to calculate the depthintegrated resistive stresses. Bed topography data from the University of Kansas are combined with surface elevation data for each epoch in order to determine changes in ice thickness. Because there was no airborne flight over Jakobshavn Isbræ in 1995, the assumption is made that from 1995 to 1997, changes in surface elevation were small (Csatho and others, 2008) and the 1997 surface elevations are applied in the 1995 force-budget calculation. No lidar was flown in 2000, so to estimate the surface DEM for that year, the 1997 and 2005 DEMs were linearly interpolated through time. This interpolation scheme was validated by comparison with data collected from 1999 and 2001 lidar flights. While this procedure may introduce additional errors in ice thickness, these are relatively minor $(<10 \mathrm{~m})$, and resulting errors in the resistive terms associated with gradients in longitudinal stress and lateral drag are small $(<10 \mathrm{kPa})$ and do not affect the main conclusions. Errors in ice thickness associated with errors in surface elevation are relatively minor. For the driving stress, on the other hand, small errors in surface elevation translate into large errors in surface slope and the estimated driving stress. For this reason, driving stress is only calculated for the times where accurate surface elevations are available (1997 and 2005). Consequently, basal drag can only be estimated for 1995 (using the 1997 driving stress) and 2005.

\subsection{Surface velocity}

Ice-flow velocity was measured from satellite interferometric image pairs in October 1995, October 2000 and October 2005 (Joughin and others, 2004, 2008a). The velocities were determined using standard speckle-tracking techniques applied to RADARSAT image pairs separated by 24 days with estimated errors of $\pm 3 \%$ and gridded with a spatial resolution of $500 \mathrm{~m}$ (Joughin and others, 2002).

\subsection{Flowline and transects}

Owing to the curvilinear nature and the small aspect ratio of the lower channel, it is impractical to calculate a full threedimensional force-balance analysis using the traditional method of superimposing a grid with a single axis oriented parallel to the direction of flow (e.g. Whillans and others, 1989; O'Neel and others, 2005). For this study, a widthaveraged force balance is calculated, with the curvilinear central flowline delineating the $x$-axis and a series of crosssectional transects representing local $y$-axes. The westernmost transect is $\sim 250 \mathrm{~m}$ upstream of the 2006 terminus 


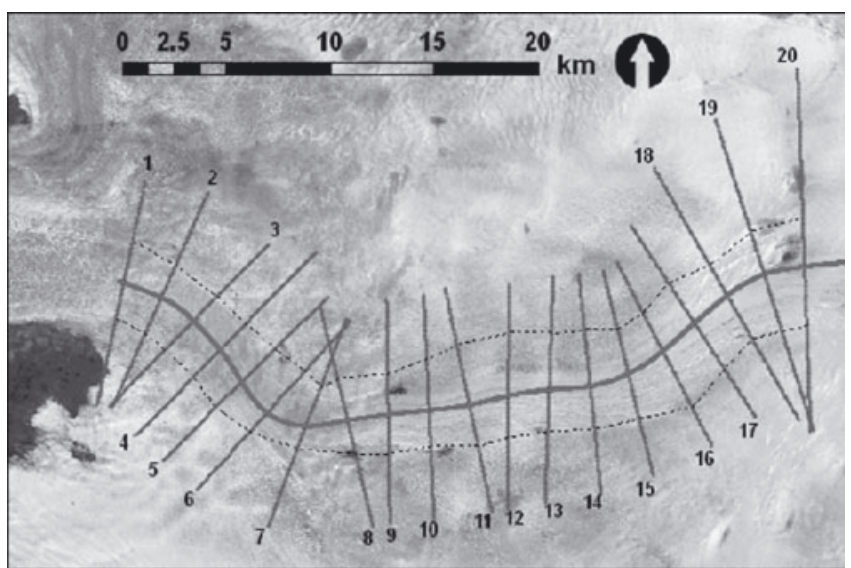

Fig. 1. Map showing the central flowline and location of transects locally perpendicular to the flow of the ice stream. Dotted curves show the boundaries of the ice stream, defined as that part of the glacier where lateral drag provides resistance to flow.

position and is located at the westernmost radar sounding in a 2006 along-flow channel flight. Nineteen additional transects are plotted at $\sim 1900 \mathrm{~m}$ intervals on, and perpendicular to, the central flowline upstream and eastward to a distance of $\sim 38 \mathrm{~km}$ from the front. The transects extend $5 \mathrm{~km}$ in both directions of the central flowline (Fig. 1).

Channel boundaries for each transect are defined by the two inflection points of the transverse velocity gradient, $\partial U / \partial y$. These inflection points correspond to the minimum and maximum lateral shear stress, $R_{x y}$ indicating the transverse location on the ice stream where the role of lateral drag changes from resisting the driving stress on the fast-moving part to acting in conjunction with the driving stress in dragging outboard slower-moving ice downstream (Whillans and Van der Veen, 1997; Van der Veen and others, 2007). Figure 2 illustrates the procedure for determining icestream width. Figure $2 \mathrm{a}$ shows the velocity perpendicular to the selected transect and Figure $2 b$ shows the lateral shear stress. The minimum and maximum shear stress define the boundaries of the ice stream. The distance along the transect between these channel boundary points is taken to be the channel width. Using this technique, the channel boundaries for each transect were very similar for all three years considered in this study. Because of this, and in the interest of consistency, the average boundary position between all years was calculated (Fig. 1) and a uniform channel width at each transect was adopted.

\subsection{Force balance}

For each transect and epoch considered, the width-averaged surface velocity, $U$, ice thickness, $H$, surface elevation, $h$, and their average errors are calculated from the measurements and used to evaluate force balance along the ice stream (following techniques outlined in Van der Veen and Whillans, 1989). The width-averaged driving stress, $\tau_{\mathrm{d}}$, is calculated from

$$
\tau_{\mathrm{d}}=-\rho g H \frac{\partial h}{\partial x},
$$

where $x$ represents the flow direction, $\rho=917 \mathrm{~kg} \mathrm{~m}^{-3}$ is the density of ice, and $g=9.8 \mathrm{~m} \mathrm{~s}^{-2}$ is the gravitational acceleration. At any transect location, surface slopes are estimated from width-averaged surface elevations at the two bounding transects (roughly $4 \mathrm{~km}$ distance). Because the

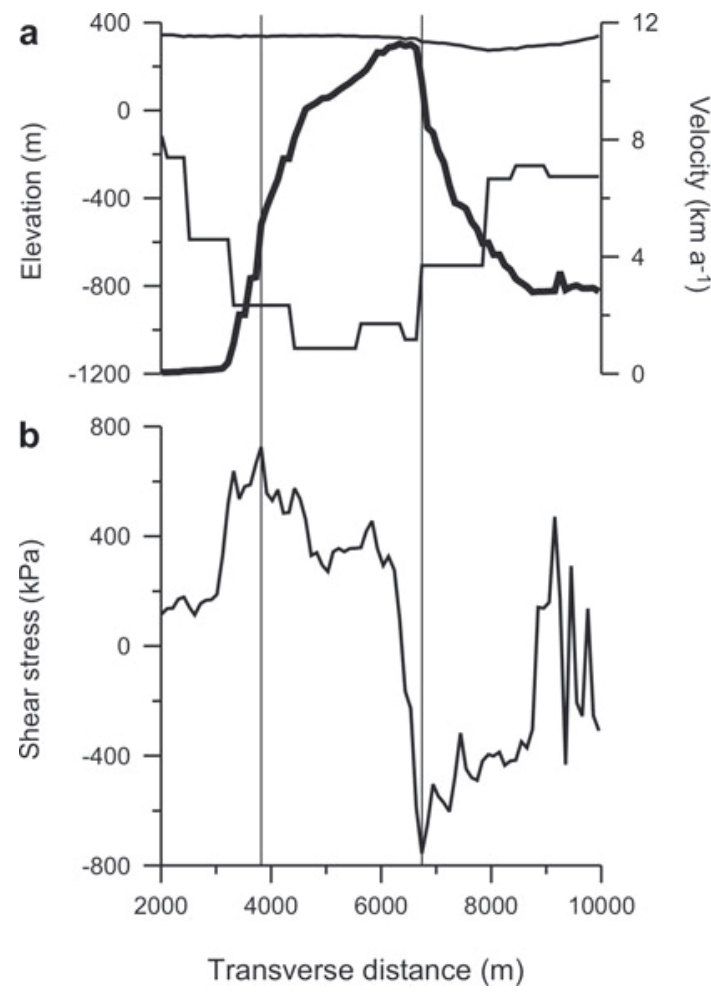

Fig. 2. (a) Surface and bed elevation (scale on the left) and 2005 surface velocity (bold curve; scale on the right) across transect 2 . (b) Lateral shear stress. Vertical lines mark maximum and minimum in shear stress and are taken to be the positions of the lateral margins of the ice stream.

driving stress is sensitive to small variations in surface slope, $\tau_{\mathrm{d}}$ is calculated only for 1997 and 2005 for which accurate surface elevations are available. Because elevation changes prior to 1997 were small (Csatho and others, 2008) the 1997 driving stress is applied to the 1995 force budget to infer basal drag. The lack of accurate surface elevations in 2000 precludes estimating basal drag for that time.

Neglecting the contribution of shear strain rates to the effective strain rate, the longitudinal resistive stress $R_{x x}$ is related to the stretching rate $\dot{\varepsilon}_{x x}$ by invoking the flow law

$$
R_{x x}=2 B \dot{\varepsilon}_{x x}^{1 / n},
$$

where $n=3$ is the flow-law exponent and $B$ is the temperature-dependent viscosity parameter (related to the rate factor as $\left.B=A^{-1 / n}\right)$. Strain rates are calculated from measured surface velocities and taken to be constant with depth. The high surface speeds suggest that most if not all flow is associated with basal sliding or with enhanced deformation of a soft basal layer (Lüthi and others, 2002), in which case the velocity is constant over all or most of the ice thickness. The implication of this assumption is that resistive stresses may be overestimated. Following Thomas (2004), the value $B=400 \mathrm{kPa} \mathrm{a}^{1 / 3}$ is adopted here, corresponding to an effective ice temperature (depth-averaged) of $-10^{\circ} \mathrm{C}$. Resistance to flow associated with along-flow tension and compression is given by

$$
F_{\text {lon }}=-\frac{\partial\left(H R_{x x}\right)}{\partial x}
$$

Gradients are evaluated from values at two bounding transects. Negative values of $F_{\text {lon }}$ act in conjunction with driving stress, while positive values resist driving stress. 
Averaged over the width, $W$, of the ice stream, resistance associated with lateral drag, $F_{\text {lat, }}$ is given by

$$
F_{\text {lat }}=\frac{H_{\mathrm{n}} R_{x y, \mathrm{n}}-H_{\mathrm{s}} R_{x y, \mathrm{~s}}}{W},
$$

where the subscripts $\mathrm{n}$ and $\mathrm{s}$ refer to values at the northern and southern shear margins, respectively (Van der Veen, 1999, section 5.8). The lateral shear stress, $R_{x y}$ is estimated from the shear strain rate, $\dot{\varepsilon}_{x y}$, as

$$
R_{x y}=2 B_{\mathrm{m}} \dot{\varepsilon}_{x y}^{1 / n} .
$$

Again, the shear strain rate is assumed constant over the ice thickness. Using a viscosity parameter $B_{\mathrm{m}}=400 \mathrm{kPa}^{1 / 3}$ results in $F_{\text {lat }}$ values for 2005 that exceed the combined effects of driving stress and longitudinal stress gradients in the lower channel, resulting in negative basal drag. Because negative basal drag is physically unrealistic, the value of the viscosity parameter at the shear margins, $B_{\mathrm{m}}$, was lowered to $300 \mathrm{kPa}^{1 / 3}$ for all three times, possibly accounting for softer ice due to localized strain heating and fabric development.

Drag at the glacier bed, $\tau_{\mathrm{b}}$, cannot be estimated independently and is obtained from the requirement that forces acting on the glacier must balance, i.e.

$$
\tau_{\mathrm{b}}=\tau_{\mathrm{d}}-F_{\text {lon }}-F_{\text {lat }} \text {. }
$$

Basal drag is estimated for 1995 and 2005, making the approximation that the 1997 driving stress can be applied to 1995.

Because of the geometry of the bedrock channel, the term 'basal drag' may be somewhat misleading as this commonly refers to flow resistance on a bed with little topographic relief in the transverse direction. In this case, the channel is narrow with steeply sloping side-walls, and basal drag includes all resistance originating at the valley walls under the main part of the ice stream. Arguably, some of the resistance included should be considered lateral drag similar to valley walls impeding the flow of mountain glaciers. For brevity of the discussion, this distinction is not made here explicitly.

In addition to determining the force-balance terms using the above formulas, associated errors are calculated using standard formulas for error propagation. The resulting equations for errors in the results are rather lengthy and are not discussed in this contribution (see Taylor, 1997, ch. 3).

\section{RESULTS}

\subsection{Driving stress}

Surface elevations averaged over the width of the glacier (Fig. 3a) reveal along-flow thinning between 1997 and 2005. Thinning is most pronounced towards the terminus, but does persist to $\sim 40 \mathrm{~km}$ inland. Thinning increased progressively from $\sim 34 \mathrm{~m}$ at $37 \mathrm{~km}$ from the 2006 calving-front position to $\sim 120 \mathrm{~m}$ close to the 2006 terminus (at $x=0$ in Fig. 3 ). The corresponding increase in large-scale surface slope $\left(2 \times 10^{-3}\right.$ over $37 \mathrm{~km}$ ) resulted in an average increase in driving stress of $\sim 20 \mathrm{kPa}$.

At each transect, the driving stress is calculated from the width-averaged surface elevation at the two neighboring transects and thus represents an average over about two to three ice thicknesses. Figure $3 \mathrm{~b}$ shows that the driving stress is significantly higher than what has been found on other ice streams (10-20 kPa; Whillans and others, 1989) or previously estimated for Jakobshavn (208 kPa; Truffer and Echelmeyer, 2003). Over the interval 1997-2005, the

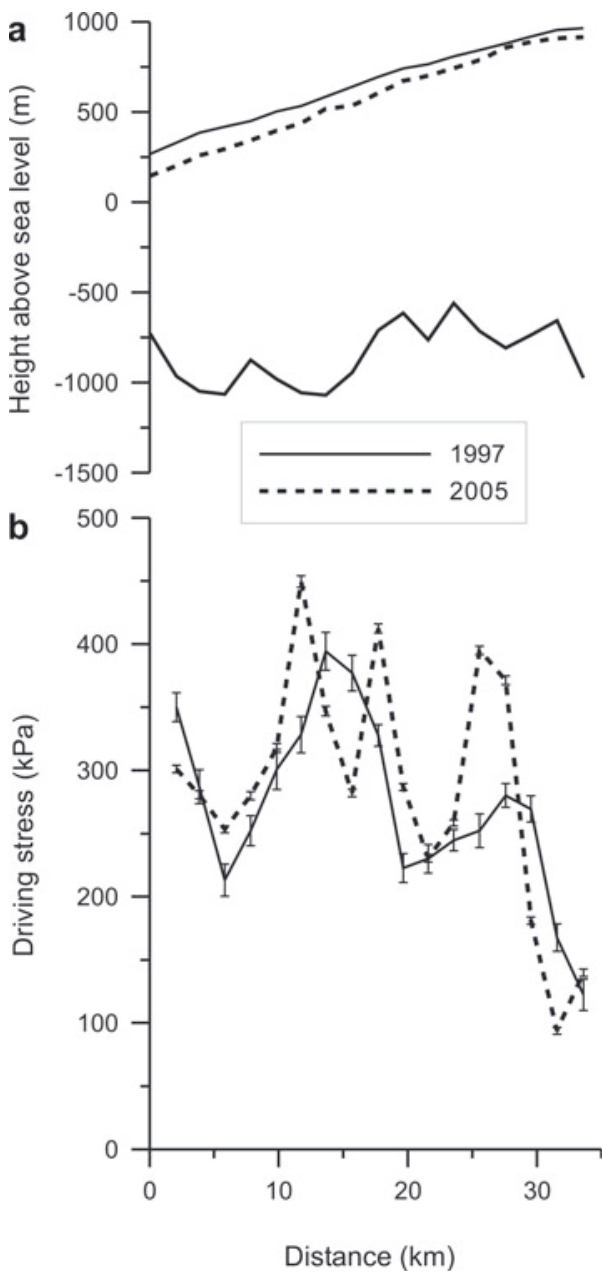

Fig. 3. (a) Width-averaged surface elevation for 1997 and 2005 and bed topography along the lower $35 \mathrm{~km}$ of the main channel. (b) Corresponding driving stress.

width-averaged driving stress averaged over the entire flowline segment increased from 276 to $296 \mathrm{kPa}$, corresponding to the overall steepening of the ice surface. Locally, changes in driving stress exceed $100 \mathrm{kPa}$ but it is not evident that these local changes are real or reflect different resolutions of the surface DEMs. Fewer laser data are available for 1997 than for 2005 and it is possible that the earlier DEM does not fully capture some of the small-scale surface features present in the 2005 DEM. For the purpose of this study - investigating the possible causes for speed-up these small-scale effects are not important. The main conclusion relevant to the large-scale dynamics of Jakobshavn Isbræ is that the average driving stress increased by only a small amount, $<10 \%$ over the lower region.

Figure 3 shows the existence of a distinct pattern of alternating low and high values of driving stress that appears to be stationary. These waves are likely linked to bedrock topography that induces small-scale variations in surface elevation. We note the similarity between these waves and those observed by Reusch and Hughes (2003) on Byrd Glacier who attributed the waves to sites of higher and lower basal resistance.

\subsection{Gradients in longitudinal stress}

The longitudinal stress, $F_{\text {lon, }}$ is linked directly to the stretching rate and thus to along-flow velocity gradients. Width-averaged velocities are shown in Figure 4 and 

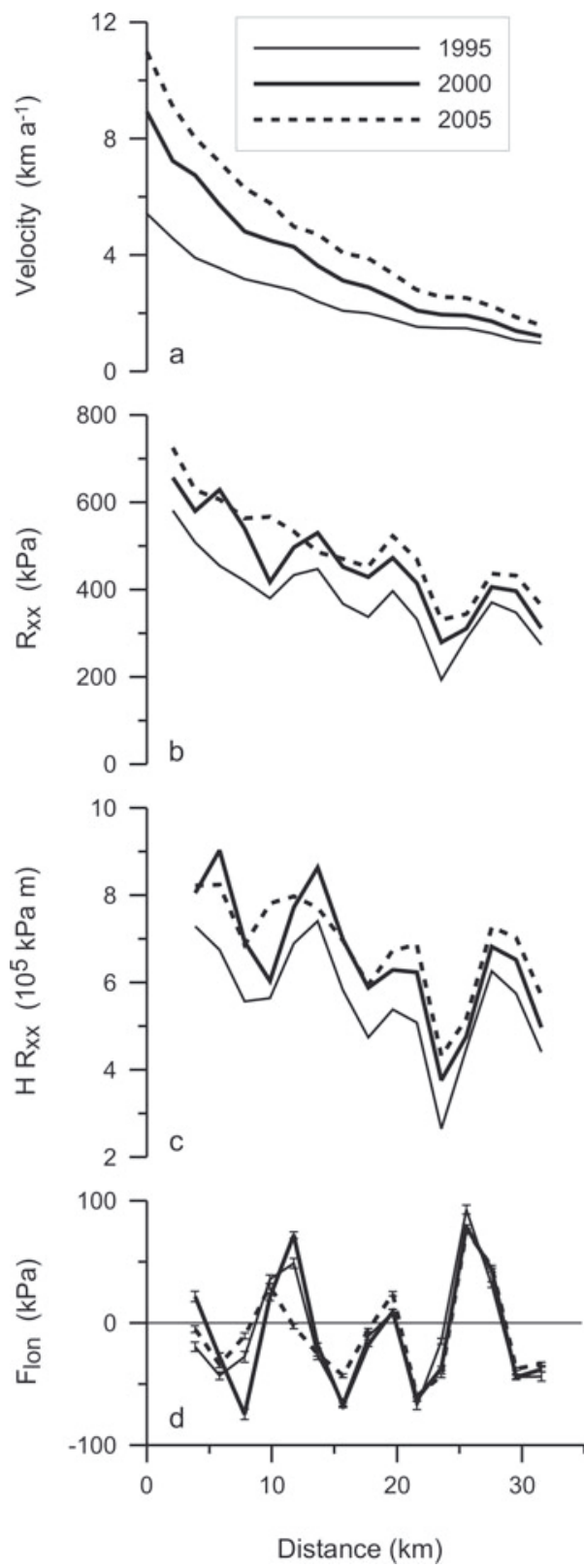

Fig. 4. (a) Width-averaged surface velocity for each of the three years considered. (b) Longitudinal resistive stress, $R_{x x}$. (c) $H R_{x x}$. (d) Gradients in longitudinal stress.

indicate that at $\sim 37 \mathrm{~km}$ from the 2006 front, surface velocities increased slightly less than 50\% between 1995 and 2005. In the lower $40 \mathrm{~km}$, the three sets of velocities increasingly diverged in the downstream direction until reaching their maxima at the terminus. At the 2006 front position, velocities were $5423 \mathrm{~m} \mathrm{a}^{-1}$ in $1995,8924 \mathrm{ma}^{-1}$ in 2000 and $10980 \mathrm{~m} \mathrm{a}^{-1}$ in 2005 , corresponding to a $\sim 100 \%$ speed increase.

The large speeds and associated stretching lead to corresponding longitudinal stresses of several hundred $\mathrm{kPa}$ (Fig. 4b). Over the period considered, $R_{x x}$ increased along the entire glacier segment considered in this study. However, gradients in longitudinal stress multiplied by the ice thickness (Fig. 4c), as called for in the force-balance equation, remained small throughout the speed-up (Fig. 4d). A linear regression on the curves in Figure 4c gives an average contribution to the large-scale force balance of $\sim 10 \mathrm{kPa}$. Because gradients in longitudinal stress

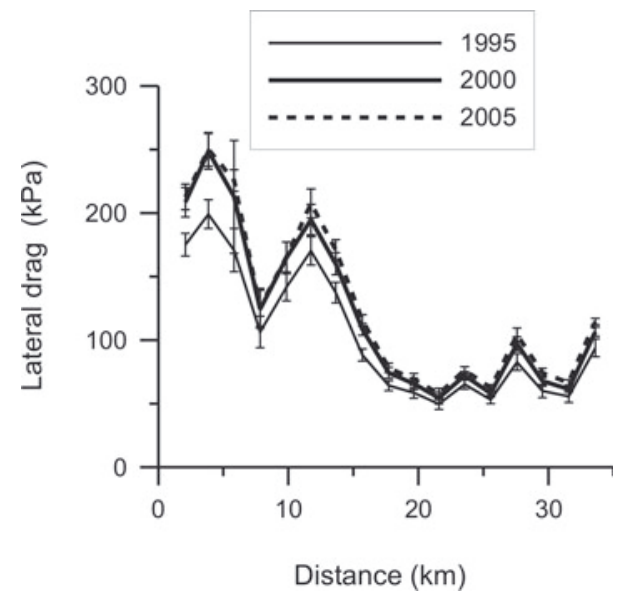

Fig. 5. Resistance to flow from lateral drag.

are positive, this term acts together with the driving stress in moving the glacier forward.

Spatial variations similar to those observed in the driving stress are present in the curves for $F_{\text {lon; }}$ however, over the 10 year period considered, maxima and minima appear to have remained stationary and we propose that these local variations are linked to bed topography.

\subsection{Lateral drag}

Near the terminus, lateral drag contributes $\sim 200 \mathrm{kPa}$ to flow resistance, decreasing towards the interior to $<100 \mathrm{kPa}$ (Fig. 5). The greatest increase in lateral drag occurred over the period 1995-2000; the subsequent change from 2000 to 2005 is much smaller and within error limits.

\subsection{Basal drag}

Resistance originating at the glacier bed is estimated from Equation (6) to satisfy the requirement that the sum of all forces acting on a section of the glacier must be zero. Near the calving front, basal drag is small and decreased by $\sim 50 \mathrm{kPa}$ throughout the speed-up (Fig. 6). Maximum basal resistance occurs $\sim 20 \mathrm{~km}$ upstream of the 2006 calving front; farther inland, this source of resistance decreases as driving stress decreases. Considered over the entire segment, average basal drag decreased slightly from $186 \mathrm{kPa}$ in 1995 to $181 \mathrm{kPa}$ in 2005.

\subsection{Large-scale force balance}

Table 1 summarizes the results of the force-budget calculations and gives the various terms averaged over the length of the glacier considered in this study. Driving stress increased by $20 \mathrm{kPa}$ and most of this increase was balanced by an increase in lateral drag.

\section{INTERPRETATION}

\subsection{Release of back-stress}

According to the buttressing hypothesis (e.g. Hughes, 1986; Howat and others, 2008; Joughin and others, 2008a), the speed-up of Jakobshavn Isbræ resulted from loss of backstress as the floating ice tongue weakened and disintegrated. Resistance to flow arises when a floating ice tongue pushes against, over or past an obstruction and may be crucial to the stability of the grounded part of the glacier by reducing the stretching rate at the grounding line. 


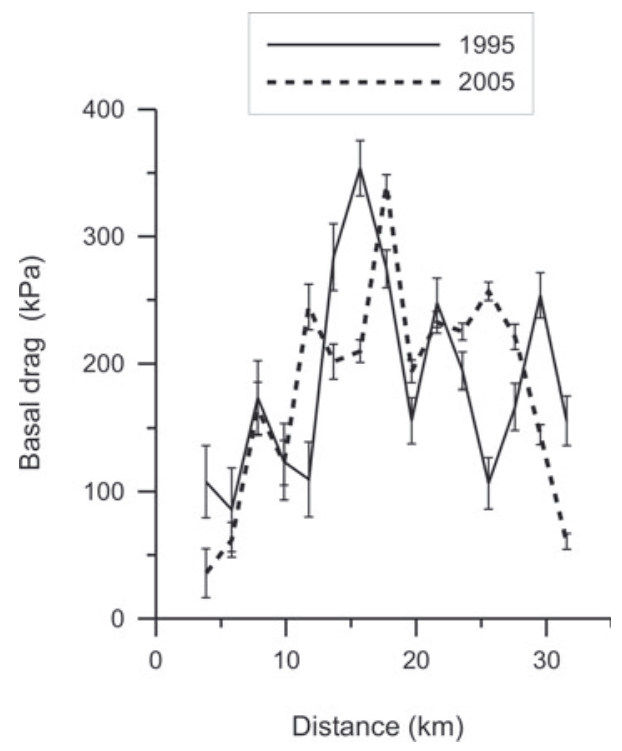

Fig. 6. Resistance to flow from basal drag.

As originally described, back-stress (or 'back-force') applies to a floating ice shelf and represents 'the total force transmitted upstream by forces, other than the pressure of sea water at the ice front, that oppose the spreading of the ice shelf' (Paterson, 1994, p. 298). In other words, back-stress represents the amount by which the stretching stress $R_{x x}$ is reduced compared with the value for a free-floating ice shelf. For a free-floating ice tongue spreading in one direction only, this stretching stress is given by (Weertman, 1957; Van der Veen, 1999, section 5.6)

$$
R_{x x}^{(0)}=\frac{1}{2} \rho g\left(1-\frac{\rho}{\rho_{\mathrm{w}}}\right) H,
$$

where $\rho_{\mathrm{w}}$ represents the density of sea water $\left(1025 \mathrm{~kg} \mathrm{~m}^{-3}\right)$ and the superscript ( 0 ) denotes the solution in the absence of lateral drag or pinning points. Where the ice tongue is bounded by fjord walls, part or all of the driving stress is balanced by lateral drag and this results in reduced alongflow spreading. At any point on the ice tongue, the backstress $\sigma_{\mathrm{b}}$ is defined as the down-glacier integrated resistance associated with lateral drag (Van der Veen, 1999, section 5.6):

$$
\sigma_{\mathrm{b}}(x)=\frac{1}{H} \int_{x}^{G} \frac{2 H \tau_{\mathrm{s}}}{W} \mathrm{~d} \bar{x},
$$

in which $\tau_{\mathrm{s}}$ represents the lateral shear stress at the fjord walls, $W$ is the width of the fjord and $x=G$ is the position of the calving front. Correspondingly, the stretching stress is reduced to

$$
R_{x x}(x)=R_{x x}^{(0)}(x)-\sigma_{\mathrm{b}}(x) .
$$

The magnitude of the back-stress depends on the strength and structural integrity of the floating part and is not known a priori. However, an estimate can be made using the present results, assuming that Equation (7) can be applied to the 2006 calving-front position in all three epochs. Note that, in doing so, the estimated back-stress also includes basal resistance on the terminal portion seaward of the 2006 calving-front position that was grounded in earlier years. Comparison of this free-floating solution to the resistive stress obtained from measured velocity gradients allows the back-stress to be estimated. Results are summarized in Table 2, noting that
Table 1. Force-balance terms for 1995 and 2005. Note that the 1997 value of driving stress is used to estimate basal drag in 1995

\begin{tabular}{llc}
\hline $\begin{array}{l}\text { Force-balance term } \\
\mathrm{kPa}\end{array}$ & $1995(1997)$ & 2005 \\
\hline$\tau_{\mathrm{d}}$ & $276 \pm 12$ & $296 \pm 3$ \\
$F_{\text {lon }}$ & $-10 \pm 3$ & $-8 \pm 2$ \\
$F_{\text {lat }}$ & $100 \pm 7$ & $123 \pm 6$ \\
$\tau_{\mathrm{b}}$ & $186 \pm 23$ & $181 \pm 11$ \\
\hline
\end{tabular}

$R_{x x}(0)$ is estimated from extrapolation of the curves in Figure $4 \mathrm{~b}$. To convert measured strain rate to resistive stress $R_{x x}$ a viscosity parameter $B=400 \mathrm{kPa} \mathrm{a}^{1 / 3}$ was applied. This produces values that are greater than the stretching stress for a free-floating ice tongue. Selecting a value for $B$ that corresponds to ice close to the melting point lowers $R_{x x}$ values to below those predicted by Equation (7). The last column in Table 2 gives the corresponding back-stress for the lower value for $B$; the results suggest a reduction of $60 \mathrm{kPa}$ from 1995 to 2000 and a further decrease of $90 \mathrm{kPa}$ between 2000 and 2005. These estimates for $\sigma_{\mathrm{b}}(0)$ are likely to represent upper limits and are used next to evaluate the effect of release of back-stress on flow up-glacier.

\subsection{Transmission of longitudinal stress}

A decrease in back-stress at the grounding line must be balanced by increased flow resistance on the grounded part and either lateral drag or basal drag must increase to accommodate the increase in glacier speed. Howat and others $(2005,2008)$ assume that this increase is equally distributed over the coupling length $L$ taken to be about 15 times the ice thickness. Kamb and Echelmeyer (1986) suggest a shorter coupling length of about seven ice thicknesses $(\sim 7 \mathrm{~km})$, while the coupling-length formula derived from scaling principles in Hindmarsh (2006, p. 1755) gives $L=4 \mathrm{~km}$. Integrating Equation (3) from $x=0$ to $x=\mathrm{L}$, gives

$$
\int_{0}^{L} F_{\text {lon }} \mathrm{d} x=H(0) R_{x x}(0)-H(L) R_{x x}(L) .
$$

Averaged over the distance $L$, resistance associated with gradients in longitudinal stress is

$$
\bar{F}_{\text {lon }}=\frac{1}{L}\left[H(0) R_{X X}(0)-H(L) R_{X X}(L)\right] .
$$

If the coupling length represents the distance over which changes in back-stress are transmitted up-glacier, $R_{x x}(L)$

Table 2. Comparison between stretching stress estimated from measured surface speeds, $R_{x x}(0)$, and the solution for a free-floating ice tongue, $R_{x x}^{(0)}(0)$, and inferred back-stress at the grounding line, $\sigma_{\mathrm{b}}(0) . H(0)$ represents ice thickness at the grounding line

\begin{tabular}{cccccc}
\hline Year & $H(0)$ & $R_{x x}^{(0)}(0)$ & $\begin{array}{c}R_{x x}(0) \\
\mathrm{B}=400 \mathrm{kPa} \mathrm{a}^{1 / 3}\end{array}$ & $\begin{array}{c}R_{x x}(0) \\
\mathrm{B}=200 \mathrm{kPa} \mathrm{a}^{1 / 3} \mathrm{~B}=200 \mathrm{kPa} \mathrm{a}^{1 / 3}\end{array}$ \\
\hline 1995 & 990 & 485 & 670 & 335 & 150 \\
2000 & 950 & 466 & 750 & 375 & 91 \\
2005 & 870 & 426 & 850 & 425 & 0 \\
\hline
\end{tabular}




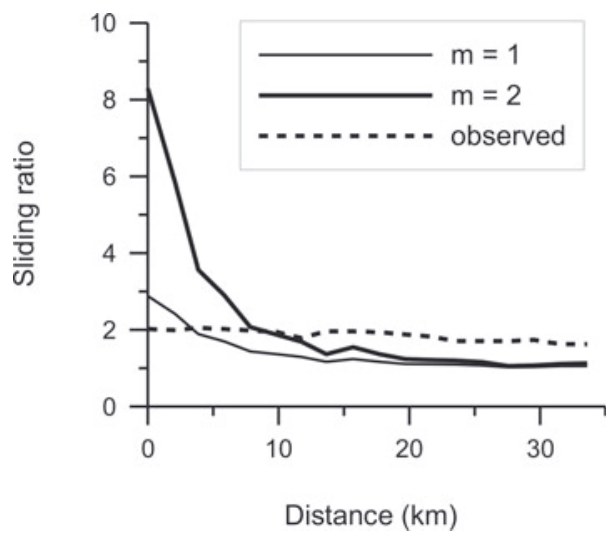

Fig. 7. Ratio of effective basal pressure in 1997 and 2005 for two values of the exponent $m$ in the sliding relation (Equation (13)) and observed ratio of surface velocity in 2005 and 1995.

remains unchanged and, ignoring for simplicity variations in ice thickness over time, the average decrease in $\bar{F}_{\text {lon }}$ is

$$
\Delta \bar{F}_{\text {lon }}=\frac{H(0)}{L} \Delta R_{x x}(0) .
$$

With $H(0)=1000 \mathrm{~m}$ (slightly greater than the measured 1995 grounding-line thickness), $L=15 \mathrm{~km}$ (Howat and others, $2005,2008)$ and $\Delta R_{x x}(0)=60 \mathrm{kPa}$, this gives $\Delta \bar{F}_{\text {lon }}=4 \mathrm{kPa}$. In other words, a lowering of back-stress of $60 \mathrm{kPa}$ at $x=0$ requires an increase in resistive forces of $4 \mathrm{kPa}$ averaged over the lower $15 \mathrm{~km}$ of the glacier. Using a smaller coupling length of $L=4 \mathrm{~km}$ (Hindmarsh, 2006), the required average increase in resistive forces is $15 \mathrm{kPa}$. Compared with a driving stress ranging from 200 to $400 \mathrm{kPa}$, such minor adjustments are inconsequential and cannot explain the observed large changes in glacier speed.

It could be argued that initially the increase in stretching stress is balanced by a greater increase in resistive stresses but over a shorter distance than the coupling length $L$. To investigate this possibility, consider the increase in lateral drag across the lowermost transect. In 1995, the widthaveraged speed (at transect 1 in Fig. 1 or $x=0$ in Figs 3-7) was $5.4 \mathrm{~km} \mathrm{a}^{-1}$ and lateral drag provided $175 \mathrm{kPa}$ to flow resistance; in 2000, the speed had increased to $8.9 \mathrm{~km} \mathrm{a}^{-1}$ and lateral drag amounted to $209 \mathrm{kPa}$ (Fig. 5). Assuming this increase in flow resistance from lateral drag acted over the $2 \mathrm{~km}$ distance separating the first and second transect, this would have been sufficient to balance a lowering of backstress at $x=0 \mathrm{~km}$ of $68 \mathrm{kPa}$. At the same time, the driving stress decreased slightly (Fig. 3b). A greater reduction in $\sigma_{\mathrm{b}}(0)$ could have been compensated for in $\sim 2 \mathrm{~km}$ from the grounding line, and farther up-glacier $R_{x x}$ would have remained unchanged. Yet our results show that the stretching stress increased over the entire length of the glacier considered in this study (Fig. 4).

From these considerations, the hypothesis that the speedup and retreat of Jakobshavn Isbræ resulted from the breakup of its floating ice tongue should be rejected. The associated decrease in back-stress was too small to significantly affect the stress distribution of the region under consideration here. Perhaps the reduction in $\sigma_{\mathrm{b}}(0)$ allowed the speed at the grounding line to increase, but because gradients in longitudinal stress remained small, this stress perturbation was not transmitted up-glacier, except perhaps through adjustments of the glacier profile, if any. While the present study only considers three time periods separated by 5 years each, velocity determinations at higher temporal resolution show that changes in glacier speed occur almost instantaneously along the lower $30-40 \mathrm{~km}$ of the glacier (Joughin and others, 2008a). If indeed these speed changes resulted solely from changes in boundary conditions at the glacier's lower end, one would expect a kinematic wave of adjustment to travel up-glacier.

\subsection{Approach to flotation}

Pfeffer (2007) proposed an instability mechanism based on the behavior of a sliding law that relates sliding speed inversely to the effective basal pressure. As the glacier thins the effective basal pressure decreases, resulting in an increase in sliding speed that may be substantial if the ice thickness approaches the flotation thickness and the effective basal pressure approaches zero. The available data can be used to investigate whether this mechanism could have played a role during the speed-up of Jakobshavn Isbræ.

It must be noted that it is not evident that the large speeds on Jakobshavn Isbræ are due to sliding over a welllubricated bed. Iken and others (1993) and Lüthi and others (2002) suggest that most of the fast motion is due to enhanced deformation in a soft basal layer. In that case, lamellar flow may be a more appropriate model and the ice velocity would be independent of effective basal pressure. This model is explored further in section 4.4. Furthermore, Luckman and Murray (2005) found that the speed-up began in spring 1998, which would have preceded the onset of significant thinning (Thomas, 2004). However, here we explore all previously suggested explanations for the rapid increase in speed on Jakobshavn Isbræ, including the model proposed by Pfeffer (2007).

Following Pfeffer (2007), the sliding speed $U_{\mathrm{s}}$ is related to basal drag and effective pressure $P_{e}$ as

$$
U_{\mathrm{s}}=A_{\mathrm{s}} \frac{\tau_{\mathrm{bx}}^{n}}{P_{\mathrm{e}}^{m}}
$$

where $A_{\mathrm{s}}$ is a sliding parameter and the value of the exponent $m$ is between 1 and 3 . If an easy connection exists between the subglacial drainage system and the ocean, the effective pressure equals the difference between ice overburden and hydrostatic pressure (Van der Veen, 1999, section 4.6):

$$
P_{\mathrm{e}}=\rho g H-\rho_{\mathrm{w}} g D,
$$

where $D$ represents the depth of the glacier bed below sea level. The additional pressure head required to drive water from the subglacial system is ignored.

During speed-up, basal drag did not change in an important way, so it is considered constant in the following analysis. If the sliding parameter can also be considered constant, the ratio of sliding velocity in 1997 to that in 2005 follows from

$$
\frac{U_{\mathrm{s}}(2005)}{U_{\mathrm{s}}(1997)}=\left(\frac{P_{\mathrm{e}}(1997)}{P_{\mathrm{e}}(2005)}\right)^{m} .
$$

The ratio of effective pressures is shown in Figure 7 for $m=1$ and $m=2$. Also shown is the ratio of observed surface speeds in 2005 and 1995. This latter ratio is assumed to be a proxy for the relative increase in sliding speed (left-hand side of Equation (15)).

Comparison of the curves in Figure 7 shows that, depending on the value chosen for the exponent $m$, the 
decrease in effective pressure due to glacier thinning can explain the increase in glacier speed over the lower 4-10 km. Farther up-glacier, however, the increase in surface speed is more than can be explained by the decrease in effective basal pressure. This suggests that, while glacier thinning and increased sliding may have contributed to glacier speed-up near the terminus, other processes must have played a role in causing the acceleration farther up-glacier.

\subsection{Change in subglacial hydrology}

An additional hypothesis is that the observed speed increase is related to changes in subglacial hydrology. The drainage model described by Equation (14) assumes an easy connection between the subglacial drainage system and the adjacent ocean. The associated subglacial water pressure represents the minimum pressure required to discharge water over a sloping bed and towards the grounding line (Van der Veen, 1999, section 4.6). Where drainage is impeded, higher water pressures are needed for water to move down-flow. These higher water pressures lower the effective basal pressure and increase sliding speed according to the sliding relation (Equation (13)).

There is abundant evidence for changes in sliding speed associated with changes in subglacial hydrology caused by variations in the amount of water supplied to the glacier bed (e.g. Lappegard and others, 2006; Harper and others, 2007; Bartholomaus and others, 2008; Flowers, 2010). In particular during spring and early summer, large volumes of water may exceed the drainage capacity of existing passageways, resulting in temporary water storage in a pressurized drainage system. However, subglacial conduits respond by becoming more efficient over the course of the summer. Consequently, there are seasonal variations in glacier speed but no long-term sustained elevated speeds have been observed to result from hydrological changes. In the case of Jakobshavn Isbræ, continued increase in speed suggests that the subglacial drainage system is becoming increasingly inefficient over time, which appears to be an unlikely scenario. In fact, Van de Wal and others (2008) show a positive relation between surface melt and ice velocity on a seasonal timescale in the ablation zone in West Greenland. Over the entire 17 year duration of their measurement campaign, however, annual ice velocities decreased slightly despite a significant increase in ablation rate, suggesting the drainage system adjusts continuously to maintain a more-orless constant annual water discharge.

Similarly, Sundal and others (2011) observed slowdown of several glaciers in West Greenland after a critical threshold in surface melting and runoff is reached. These observations are consistent with the theoretical model of Schoof (2010) that captures the dynamical transition between channelized subglacial drainage (low subglacial water pressure) and drainage through interconnected cavities (high subglacial water pressure). This model predicts that higher rates of steady water supply to the glacier base can result in a decrease in sliding speed.

\subsection{Weakening of marginal and basal ice}

Our results show that the dynamics of Jakobshavn Isbræ are controlled by basal and lateral drags balancing the driving stress. This agrees with the study of Truffer and Echelmeyer (2003) who found that observed velocities on Jakobshavn Isbræ could be modeled by assuming that lateral and basal drags balance the local driving stress. Close to the terminus,
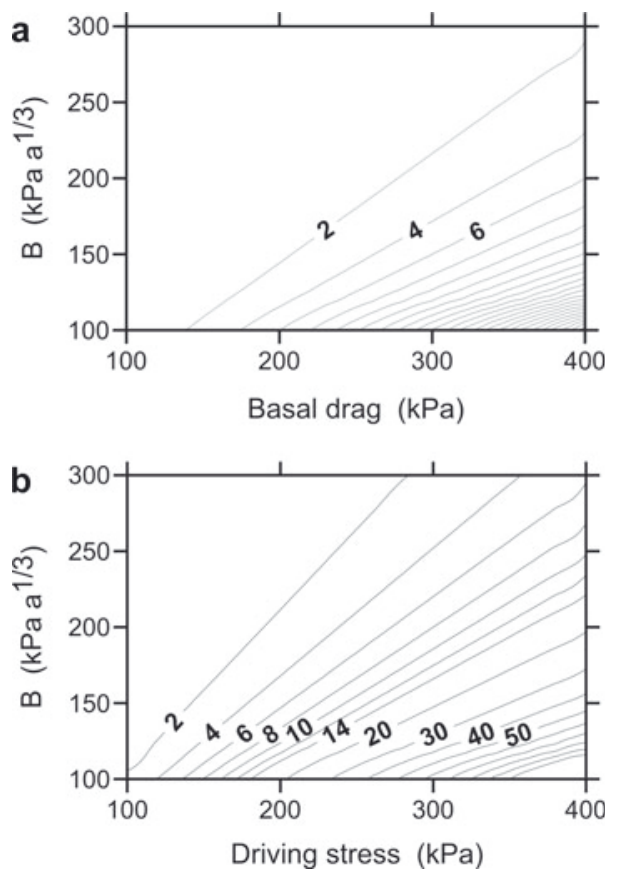

Fig. 8. (a) Contours of velocity $\left(\mathrm{km} \mathrm{a}^{-1}\right.$; contour interval $\left.2 \mathrm{~km} \mathrm{a}^{-1}\right)$ as a function of basal drag and viscosity parameter for lamellar flow. (b) Contours of velocity $\left(\mathrm{km} \mathrm{a}^{-1}\right.$; contour interval $2 \mathrm{~km} \mathrm{a}^{-1}$ up to $20 \mathrm{~km} \mathrm{a}^{-1}$ and $10 \mathrm{~km} \mathrm{a}^{-1}$ for higher values) as a function of driving stress and viscosity parameter.

lateral drag provides most of the flow resistance, while farther up-glacier basal drag becomes the dominant term and this partitioning did not change significantly over the time period considered in our study. The question is how to explain the near doubling in glacier speed. Near the terminus, speed may have increased as the glacier thinned and the effective basal pressure decreased (Fig. 7) but this cannot explain the acceleration farther inland. To address this we consider two end-member solutions, namely laminar flow in which the driving stress is balanced entirely by basal drag, and the model in which all or most of the driving stress is balanced by lateral drag. In reality, flow of Jakobshavn is a combination of these two, but the two extreme models allow us to investigate qualitatively the possible causes for the observed speed-up.

Assuming laminar flow with no contribution from basal sliding, the surface speed is given by (Van der Veen, 1999, equation (5.1.7))

$$
U(h)=\frac{2 H}{4}\left(\frac{\tau_{\mathrm{b}}}{B}\right)^{3}
$$

where $B$ is the viscosity parameter and $n=3$ is used for the flow-law exponent. The contour plot in Figure 8a shows isolines of surface speed (in $\mathrm{km} \mathrm{a}^{-1}$ ) as a function of basal drag and viscosity parameter, using an ice thickness of $H=1500 \mathrm{~m}$, the average thickness for the upper part of the ice stream. The plot shows that for values of basal drag found for Jakobshavn Isbræ (200-300 kPa; Fig. 6), a very small value for the viscosity parameter is required to produce velocities of several $\mathrm{km} \mathrm{a}^{-1}$ as observed on the glacier. This is consistent with the suggestion that the lower ice layers consist of soft temperate ice that facilitates deformation (Iken and others, 1993; Horgan and others, 2008). In the laminar flow model, in which vertical shear is concentrated near the 
glacier base, this can be accounted for by using a small viscosity parameter.

The contour plot in the lower panel of Figure 8 shows contours of surface speed for the model in which the driving stress is balanced entirely by lateral drag. In that model, the center-line speed is given by (Van der Veen, 1999, equation (5.5.16))

$$
U(c)=\frac{2}{4}\left(\frac{\tau_{\mathrm{d}}}{B H}\right)^{3}(W / 2)^{4} .
$$

In these calculations, $H=1500 \mathrm{~m}$ and $\mathrm{W}=4000 \mathrm{~m}$ (note the change in contour interval above $14 \mathrm{~km} \mathrm{a}^{-1}$ ). For a driving stress of $300 \mathrm{kPa}$ (Fig. 3), a viscosity parameter of $220 \mathrm{kPa}^{1 / 3}$ predicts a center-line speed of $\sim 6 \mathrm{~km} \mathrm{a}^{-1}$, comparable with the 1995 speed near the terminus.

The contour plots in Figure 8 show that an increase in glacier speed can be achieved by increasing basal drag or driving stress or by lowering the viscosity parameter. For $\tau_{\mathrm{b}}=250 \mathrm{kPa}$ and $B=140 \mathrm{kPaa}^{1 / 3}$, the predicted surface speed is $\sim 4 \mathrm{~km} \mathrm{a}^{-1}$ according to the laminar flow model. Doubling this speed to $8 \mathrm{~km} \mathrm{a}^{-1}$ requires a decrease in the viscosity parameter to $120 \mathrm{kPa}^{1 / 3}$ or an increase in basal drag to $\sim 320 \mathrm{kPa}$. For the second model, with driving stress balanced by lateral drag, an increase in speed from 6 to $12 \mathrm{~km} \mathrm{a}^{-1}$ requires a reduction in the viscosity parameter from 220 to $170 \mathrm{kPa} \mathrm{a}^{1 / 3}$ or an increase in driving stress from 300 to $380 \mathrm{kPa}$. For both models, explaining the observed speed-up in terms of increased resistive stress requires changes in the resistive stress that are, generally, greater than inferred from the observations (Figs 3, 5 and 6), leading to the conclusion that the likely cause for speed-up was weakening of basal or marginal ice. If this weakening resulted solely from warming of the stress-bearing part of the ice column, an increase in ice temperature of $2-3^{\circ} \mathrm{C}$ would be implied.

\subsection{Ice viscosity}

An important parameter affecting results of the force-budget analysis is the viscosity parameter in the flow law linking measured strain rates to resistive stresses. Two different values are used here, one applicable to longitudinal stresses (Equation (2)) and one for lateral shear stresses (Equation (5)). An initial value of $400 \mathrm{kPaa}^{1 / 3}$ was selected for both (following Thomas, 2004), but our analysis indicates a lower value may be more appropriate.

The viscosity parameters used here to infer resistive stresses from measured strain rates apply to the longitudinal stress $R_{x x}$ and lateral shear stress $R_{x y}$. The basal ice layer is temperate (Iken and others, 1993; Lüthi and others, 2009) and may be further softened by development of crystalorientation fabric (Horgan and others, 2008) making the ice softer by a factor of three compared with ice with a random fabric (Reeh, 1985). Thus, for linking vertical shear strain rate to vertical shear stress, a (much) smaller viscosity parameter should be used. However, this has no effect on our calculations because vertical shear is not explicitly considered and, instead, is inferred from force balance.

Using $B=400 \mathrm{kPaa}^{1 / 3}$ in Equation (2) to estimate the longitudinal resistive stress $R_{x x}$ from the along-flow stretching rate results in values of this stress that are significantly greater than values corresponding to an ice shelf spreading unimpeded in one direction (Table 2). That comparison suggests a value for the viscosity parameter about half the initially selected value, applicable to ice within a few ${ }^{\circ} \mathrm{C}$ of the melting temperature (Hooke, 1981). It is possible that the ice in the lower parts of the glacier is warmed by meltwater percolating downward into crevasses and refreezing at depth. For the present analysis and interpretation this is not an important issue. Gradients in longitudinal stress are unimportant in the large-scale balance of forces (Table 1), and selecting a smaller value for the viscosity parameter would further diminish the role of this term.

Selecting an appropriate value for the viscosity parameter used in the calculation of lateral drag is more important. A requirement is that resistance from lateral drag cannot exceed the driving stress as this would imply negative resistance at the glacier bed. This led us to adopt the value $B_{\mathrm{m}}=300 \mathrm{kPaa}^{1 / 3}$. It may be noted that with continued speed-up after 2005, a smaller value may be needed for force-balance calculations in the years following 2005. Considering the intense lateral shear across the margins, it is entirely plausible that the ice is softened locally by meltwater, strain heating and/or fabric development, resulting in a lower value for the viscosity parameter.

In our force-balance calculations, the same value for the viscosity parameter is used for all three years. If indeed the speed-up was caused by weakening of the lateral margins, lower values should be used for later years. This would reduce resistance from lateral drag in 2000 and 2005 and increase basal drag accordingly. Increased basal drag would further contribute to velocity increase. Investigating this interaction in more detail requires a model that incorporates all relevant stresses and their interactions, such as that employed by Truffer and Echelmeyer (2003).

\section{DISCUSSION}

Previous studies addressing the stability of Jakobshavn Isbræ were based on theoretical analyses (Hughes, 1986), forceperturbation modeling (Thomas, 2004) or correlation between observed events (Holland and others, 2008; Joughin and others, 2008a). The present study is the first to consider quantitatively the forces acting on the lower portion of this glacier over the 10 year period during which ice discharge doubled and rapid thinning occurred. The conclusions reached here differ substantially from these (and other) earlier studies in that no support is found for the hypothesis that the speed-up of Jakobshavn Isbræ resulted from the break-up of its floating ice tongue. For all three times considered, gradients in longitudinal stress contributed little to the large-scale balance of forces. Similarly, compared with the large driving stress found on this glacier, release of back-stress at the grounding line has too small an effect to explain the observed increase in glacier speed. A further argument against the back-stress hypothesis is that the velocity continued to increase after the floating tongue had disintegrated completely.

Along the entire $35 \mathrm{~km}$ transect considered in this study, the surface velocity increased substantially (Fig. 4). This increase cannot be explained by glacier thinning and approach to flotation (Fig. 6) nor by an increase in driving and resistive stresses. Instead, based on the contours shown in Figure 8, we surmise that the speed-up resulted from a decrease in the viscosity parameter applicable to the ice in the shear margins or to the soft basal ice layer. Available data are insufficient to point conclusively to one or the other as the cause for speed-up of Jakobshavn Isbræ, but we favor the interpretation based on weakening of the shear margins. 
Flow of Jakobshavn Isbræ is controlled by both lateral and basal drag involving both lateral and vertical shear (Truffer and Echelmeyer, 2003). Shear is most concentrated in the temperate basal layer (Iken and others, 1993) and in the lateral shear margins; an increase in speed could be caused by further enhancement of deformation in these regions.

For surging glaciers, rapid changes in glacier speed are linked to a transition in the organization of the subglacial drainage system (Fowler, 1987), but given that Jakobshavn Isbræ was moving at speeds of up to $6 \mathrm{~km} \mathrm{a}^{-1}$ before the speed-up, it is unlikely that such a transition was the main cause. Iken and others (1993) conclude that a welldeveloped subglacial drainage system exists that can accommodate additional water input without significant change in water pressure. It could be argued that this drainage system became less effective, transitioning to a linked-cavity system perhaps, resulting in higher subglacial water pressures (and lower effective pressure). However, with continued water input one would expect a more efficient drainage system to be re-established which would result in lowering ice speed, as predicted from theoretical considerations (Schoof, 2010).

Thickening of the temperate ice layer will also result in greater speeds, but there is no plausible explanation why this should occur over a relatively short time after a prolonged period of more-or-less stable glacier behavior. Finally, further weakening of the temperate ice layer also appears to be an unlikely candidate for explaining the glacier speedup. This layer, up to $400 \mathrm{~m}$ thick (Iken and others, 1993), is at the pressure-melting point (Truffer and Echelmeyer, 2003), likely with a large water content (Lüthi and others, 2002). Additional surface water reaching this deep layer is thus expected to have little effect on temperature or water content, both of which could potentially change the viscosity parameter.

Based on the above considerations, we posit that weakening of the ice in the lateral margins is the most likely cause for the velocity increase along the lower $35 \mathrm{~km}$ of Jakobshavn Isbræ. Joughin and others (2004) note that several of the speed increases coincide with major calving events, but the floating tongue did not disintegrate completely until May 2003. They argue that several large rifts in the shelf that began developing in 2000 along the northern fjord wall may have reduced lateral drag and hence the back-stress on the inland ice. Joughin and others (2004) further suggest that weakening of the floating tongue may have been initiated by abnormally high surface melting recorded at the nearby station in Egedesminde $\left(68^{\circ} 48^{\prime} \mathrm{N}\right.$, $52^{\circ} 45^{\prime} \mathrm{W} ; 47 \mathrm{~m}$ a.s.l.) (Thomas and others, 2003). Large surface ablation rates would not be restricted to the floating shelf and would extend farther inland as well. Excess meltwater at the surface tends to collect in surface ponds and marginal crevasses and provides a mechanism for warming subsurface ice. On the main trunk of the glacier this would have little effect, unless the meltwater reaches the bed perhaps, because most shearing is concentrated in the lower ice layers. At the lateral margins, however, warming of the upper few hundred meters will weaken these margins and lower resistance from lateral drag, allowing the glacier to speed up. Most of the resistance from lateral drag originates in the cold and stiffer upper portion of the ice column. Warming this upper portion can be expected to result in a significant decrease in overall column strength.
Warming of deeper ice layers occurs when surface meltwater percolates downward and refreezes at some depth. This process is most effective at shallow depths in the accumulation zone (Paterson, 1994). Phillips and others (2010) propose cryo-hydrologic warming as a mechanism for rapid warming of subsurface ice in the ablation zone. They argue that water in englacial passages, such as crevasses and moulins, with a temperature at or above freezing, heats the surrounding ice during the melt season. If liquid water is retained during the winter, sustained warming throughout the winter persists. Calculations applicable to the Sermeq Avannarleq region $(<75 \mathrm{~km}$ from Jakobshavn Isbræ) suggest warming of a few ${ }^{\circ} \mathrm{C}$ may occur in the upper $500 \mathrm{~m}$ of the ice column within a few years following the shift of the equilibrium line from 1050 to 1250 ma.s.l. (Phillips and others, 2010). Such a rapid increase in ice temperature could explain the rather sudden reduction in strength of the marginal ice of Jakobshavn Isbræ.

Another process that could affect the strength of ice in the lateral margins is hydraulic weakening. While the mechanism remains largely unknown, the weakening effect of water has been observed in different varieties of quartz and other crystals (Poirier, 1985, section 5.2.3). For polycrystalline ice, Duval (1977) found an increase in creep rate by a factor of four for an increase in water content from $<0.1 \%$ to $1 \%$. De La Chapelle and others (1999) conducted experiments comparing deformation of pure ice with very low water content and saline ice containing water, at temperatures ranging from $-13^{\circ} \mathrm{C}$ to $-5^{\circ} \mathrm{C}$. Their results suggest that a water content of a few percent can have a significant effect on the rate of deformation. Whether this process is acting in the lateral margins of Jakobshavn Isbræ is not immediately clear as it would require meltwater to remain in the liquid phase instead of refreezing at depth.

The conclusion arrived at here, that the speed-up of Jakobshavn Isbræ did not result from break-up of the floating ice tongue and consequent release of back-stress, diametrically opposes what appears to be the emerging canonical view that rapid glacier changes are driven by processes at the glacier terminus or grounding line. The essence of our argument, based on quantitative assessment of resistive forces acting on the lower trunk of Jakobshavn Isbræ prior to and during speed-up and terminus retreat, is that the reduction in back-stress at the grounding line was by itself not sufficient to affect the stress balance on the grounded part in such a way as to result in rapid accelerations extending several tens of kilometers inland. A lowering in back-stress of, for example, $100 \mathrm{kPa}$ must be balanced by increased flow resistance. Assuming this increase is equally distributed over a distance of $7-15 \mathrm{~km}$, the average increase in resistive stress is $7-14 \mathrm{kPa}$ for a thickness at the grounding line of $1000 \mathrm{~m}$. The driving stress on Jakobshavn Isbræ ranges from 200 to $400 \mathrm{kPa}$, and such minor adjustments to resistive stresses are unimportant and unable to explain the observed doubling in glacier speed.

Our force-budget calculations apply to three distinct times spanning a 10 year period and do not consider seasonal variations in glacier speed. Joughin and others (2008b) detected a seasonal increase in velocity on the fastest-moving parts of Jakobshavn Isbræ, in phase with changes at the calving front. Seasonal variations in ice 
discharge are not limited to fast-moving outlet glaciers (Van de Wal and others, 2008; Shepherd and others, 2009; Bartholomew and others, 2010) and these are attributed to seasonal adjustments of the subglacial drainage system to increased water availability (e.g. Iken and others, 1983; Iken and Bindschadler, 1986). Joughin and others (2008b) propose that fast-moving outlet glaciers such as Jakobshavn Isbræ exhibit a lower sensitivity to seasonal melting than does the surrounding more sluggish ice sheet because of their smoother beds resulting from strong erosion and because deformational heating at the glacier base provides a steady source of water able to maintain an efficient drainage system. Instead, these authors conjecture that seasonal velocity increases are likely the response to a decline in back-stress as the calving front retreats. There may be another explanation for the observed correlation between glacier speed and terminus position.

On marine-based calving glaciers, the interaction between ice melange in the fjord and rate of iceberg production may be the lurking process responsible for concomitant changes in position of the calving front and ice discharge. This melange can be modeled as a weak granular cover that exerts a restraining force on the calving front (Geirsdóttir and others, 2008; Amundson and others, 2010), possibly associated with jamming of flow where the material passes through a constriction (Johnson and others, 2004). Amundson and others (2010) estimate that the resistive force associated with the melange is too small to have a direct effect on glacier speed but may be sufficient to suppress calving during the winter months, allowing the terminus to advance. The changing geometry of the calving front may, in turn, lead to variations in glacier speed.

The modeling study of Nick and others (2010) provides some support for the hypothesis that melange concentration in the fjord indirectly influences discharge from the grounded part of a marine glacier. In that model, the position of the calving front is determined by penetration depth of surface crevasses. This depth is controlled by the local stretching rate and by the amount of water filling the crevasse. Imposing seasonal forcing either by varying the water level in crevasses or by varying the back-stress at the terminus (with an annual amplitude of $20 \mathrm{kPa}$ ) yields a similar glacier response. During the spring and summer, calving rates increase and the terminus retreats, while during the winter, calving goes almost to zero and the terminus advances with the speed of the glacier. Associated with the seasonal advance and retreat of the terminus are fluctuations in speed. As the terminus retreats, velocity increases as a result of lowered basal and lateral resistance and increased thickness at the terminus.

Our conclusions regarding the processes most likely to be responsible for recent dynamical changes on Jakobshavn Isbræ apply to that glacier only. While it is tempting to speculate about the broader impacts and applicability to other rapidly changing calving glaciers, such generalizations would be premature without quantitative analyses of these other glaciers (Chamberlin, 1965). As noted by Truffer and Echelmeyer (2003), a continuum of streaming behavior exists with different dynamical flow regimes.

\section{CONCLUSIONS}

Analysis of forces acting on Jakobshavn Isbræ at three times covering the rapid increase in ice velocity shows that observed changes did not result from weakening and break-up of the floating ice tongue. Gradients in longitudinal stress contributed negligibly to the balance of forces over the period considered. Instead, the most likely explanation for the glacier's acceleration is progressive weakening of the ice in the lateral shear margins, possibly as a result of meltwater penetration in crevasses in these shear margins.

\section{ACKNOWLEDGEMENTS}

We thank K. Jezek for many discussions and suggestions that helped improve the clarity of our analysis and I. Joughin for providing velocity data. We thank the Associate Editor, T. Scambos, and two anonymous reviewers for their insightful comments and suggestions which helped improve this 'magnificent heresy'. This research was sponsored by the US National Science Foundation under grants 0424589 and 0520427 and NASA Earth Systems Science Fellowship NNG05GO95H.

\section{REFERENCES}

Amundson, J.M., M. Fahnestock, M. Truffer, J. Brown, M.P. Lüthi and R.J. Motyka. 2010. Ice mélange dynamics and implications for terminus stability, Jakobshavn Isbræ, Greenland. J. Geophys. Res., 115(F1), F01005. (10.1029/2009JF001405.)

Bartholomaus, T.C., R.S. Anderson and S.P. Anderson. 2008. Response of glacier basal motion to transient water storage. Nature Geosci., 1(1), 33-37.

Bartholomew, I., P. Nienow, D. Mair, A. Hubbard, M.A. King and A. Sole. 2010. Seasonal evolution of subglacial drainage and acceleration in a Greenland outlet glacier. Nature Geosci., 3(6), 408-411.

Chamberlin, T.C. 1965. The method of multiple working hypotheses. Science, 148(3671), 754-759.

Csatho, B., T. Schenk, C.J. van der Veen and W.B. Krabill. 2008. Intermittent thinning of Jakobshavn Isbræ, West Greenland, since the Little Ice Age. J. Glaciol., 53(184), 131-144.

De La Chapelle, S., H. Milsch, O. Castelnau and P. Duval. 1999. Compressive creep of ice containing a liquid intergranular phase: rate-controlling processes in the dislocation creep regime. Geophys. Res. Lett., 26(2), 251-254.

Duval, P. 1977. The role of the water content on the creep rate of polycrystalline ice. IAHS Publ. 118 (Symposium at Grenoble 1975 - Isotopes and Impurities in Snow and Ice), 29-33.

Flowers, G.E. 2010. Glacier hydromechanics: early insights and the lasting legacy of three works by Iken and colleagues. J. Glaciol., 56(200), 1069-1078.

Fowler, A.C. 1987. A theory of glacier surges. J. Geophys. Res., 92(B9), 9111-9120.

Geirsdóttir, A., G.H. Miller, N.J. Wattrus, H. Björnsson and K. Thors. 2008. Stabilization of glaciers terminating in closed water bodies: evidence and broader implications. Geophys. Res. Lett., 35(17), L17502. (10.1029/2008GL034432.)

Gogineni, S., T. Chuah, C. Allen, K. Jezek and R.K. Moore. 1998. An improved coherent radar depth sounder. J. Glaciol., 44(148), 659-669.

Gogineni, S. and 9 others. 2001. Coherent radar ice thickness measurements over the Greenland ice sheet. J. Geophys. Res., 106(D24), 33,761-33,772.

Harper, J.T., N.F. Humphrey, W.T. Pfeffer and B. Lazar. 2007. Two modes of accelerated glacier sliding related to water. Geophys. Res. Lett., 34(12), L12503. (10.1029/2007GL030233.)

Hindmarsh, R.C.A. 2006. The role of membrane-like stresses in determining the stability and sensitivity of the Antarctic Ice Sheets: back pressure and grounding line motion. Philos. Trans. R. Soc. London, Ser. A, 364(1844), 1733-1767. 
Holland, D.M., R.H. Thomas, B. de Young, M.H. Ribergaard and B. Lyberth. 2008. Acceleration of Jakobshavn Isbræ triggered by warm subsurface ocean waters. Nature Geosci., 1(10), 659-664.

Hooke, R.LeB. 1981. Flow law for polycrystalline ice in glaciers: comparison of theoretical predictions, laboratory data, and field measurements. Rev. Geophys. Space Phys., 19(4), 664-672.

Horgan, H.J. and 6 others. 2008. Complex fabric development revealed by englacial seismic reflectivity: Jakobshavn Isbræ, Greenland. Geophys. Res. Lett., 35(L10), L10501. (10.1029/ 2008GL033712.)

Howat, I.M., I. Joughin, S. Tulaczyk and S. Gogineni. 2005. Rapid retreat and acceleration of Helheim Glacier, east Greenland. Geophys. Res. Lett., 32(22), L22502. (10.1029/ 2005GL024737.)

Howat, I.M., I. Joughin, M. Fahnestock, B.E. Smith and T. Scambos. 2008. Synchronous retreat and acceleration of southeast Greenland outlet glaciers 2000-2006: ice dynamics and coupling to climate. J. Glaciol., 54(187), 646-660.

Hughes, T. 1986. The Jakobshavns effect. Geophys. Res. Lett., 13(1), $46-48$.

Iken, A. and R.A. Bindschadler. 1986. Combined measurements of subglacial water pressure and surface velocity of Findelengletscher, Switzerland: conclusions about drainage system and sliding mechanism. J. Glaciol., 32(110), 101-119.

Iken, A., H. Röthlisberger, A. Flotron and W. Haeberli. 1983. The uplift of Unteraargletscher at the beginning of the melt season a consequence of water storage at the bed? J. Glaciol., 29(101), $28-47$.

Iken, A., K. Echelmeyer, W. Harrison and M. Funk. 1993. Mechanisms of fast flow in Jakobshavns Isbræ, West Greenland: Part I. Measurements of temperature and water level in deep boreholes. J. Glaciol., 39(131), 15-25

Johnson, J.V., P.R. Prescott and T.J. Hughes. 2004. Ice dynamics preceding catastrophic disintegration of the floating part of Jakobshavn Isbræ, Greenland. J. Glaciol., 50(171), 492-504.

Joughin, I., S. Tulaczyk, R.A. Bindschadler and S. Price. 2002. Changes in West Antarctic ice stream velocities: observation and analysis. J. Geophys. Res., 107(B11), 2289. (10.1029/ 2001JB001029.)

Joughin, I., W. Abdalati and M.A. Fahnestock. 2004. Large fluctuations in speed on Greenland's Jakobshavn Isbræ glacier. Nature, 432(7017), 608-610.

Joughin, I. and 7 others. 2008a. Continued evolution of Jakobshavn Isbrae following its rapid speedup. J. Geophys. Res., 113(F4), F04006. (10.1029/2008JF001023.)

Joughin, I., S.B. Das, M.A. King, B.E. Smith, I.M. Howat and T. Moon. 2008b. Seasonal speedup along the western flank of the Greenland Ice Sheet. Science, 320(5877), 781-783.

Kamb, B. and K.A. Echelmeyer. 1986. Stress-gradient coupling in glacier flow: I. Longitudinal averaging of the influence of ice thickness and surface slope. J. Glaciol., 32(111), 267-284.

Krabill, W.B., R.H. Thomas, C.F. Martin, R.N. Swift and E.B. Frederick. 1995. Accuracy of airborne laser altimetry over the Greenland ice sheet. Int. J. Remote Sens., 16(7), $1211-1222$

Krabill, W. and 12 others. 2004. Greenland Ice Sheet: increased coastal thinning. Geophys. Res. Lett., 31(24), L24402. (10.1029/ 2004GL021533.

Lappegard, G., J. Kohler, M. Jackson and J.O. Hagen. 2006. Characteristics of subglacial drainage systems deduced from load-cell measurements. J. Glaciol., 52(176), 137-148.

Luckman, A. and T. Murray. 2005. Seasonal variation in velocity before retreat of Jacobshavn Isbræ, Greenland. Geophys. Res. Lett., 32(8), L08501. (10.1029/2005GL022519.)

Luthcke, S.B. and 8 others. 2006. Recent Greenland ice mass loss by drainage system from satellite gravity observations. Science, 314(5803), 1286-1289.

Lüthi, M., M. Funk, A. Iken, S. Gogineni and M. Truffer. 2002. Mechanisms of fast flow in Jakobshavn Isbræ, West Greenland. Part III. Measurements of ice deformation, temperature and cross-borehole conductivity in boreholes to the bedrock. J. Glaciol., 48(162), 369-385.

Lüthi, M.P., M. Fahnestock and M. Truffer. 2009. Correspondence. Calving icebergs indicate a thick layer of temperate ice at the base of Jakobshavn Isbræ, Greenland. J. Glaciol., 55(191), 563-566.

Moon, T. and I. Joughin. 2008. Changes in ice front position on Greenland's outlet glaciers from 1992 to 2007. J. Geophys. Res., 113(F2), F02022. (10.1029/2007JF000927.)

Nick, F.M., C.J. van der Veen, A. Vieli and D.I. Benn. 2010. A physically based calving model applied to marine outlet glaciers and implications for the glacier dynamics. J. Glaciol., 56(199), 781-794.

O'Neel, S., W.T. Pfeffer, R. Krimmel and M. Meier. 2005. Evolving force balance at Columbia Glacier, Alaska, during its rapid retreat. J. Geophys. Res., 110(F3), F03012. (10.1029/ 2005JF000292.)

Paterson, W.S.B. 1994. The physics of glaciers. Third edition. Oxford, etc., Elsevier

Pfeffer, W.T. 2007. A simple mechanism for irreversible tidewater glacier retreat. J. Geophys. Res., 112(F3), F03S25. (10.1029/ 2006JF000590.)

Phillips, T., H. Rajaram and K. Steffen. 2010. Cryo-hydrologic warming: a potential mechanism for rapid thermal response of ice sheets. Geophys. Res. Lett., 37(20), L20503. (10.1029/ 2010GL044397.)

Plummer, J., S. Gogineni, C. van der Veen, C. Leuschen and J. Li. 2008. Ice thickness and bed map for Jakobshavn Isbræ. CReSIS Tech. Rep. 2008-1.

Poirier, J.P. 1985. Creep of crystals. Cambridge, etc., Cambridge University Press.

Reeh, N. 1985. Was the Greenland ice sheet thinner in the Late Wisconsinan than now? Nature, 317(6040), 797-799.

Reusch, D. and T.J. Hughes. 2003. Surface 'waves' on Byrd Glacier, Antarctica. Antarct. Sci., 154(4), 547-555.

Rignot, E. and P. Kanagaratnam. 2006. Changes in the velocity structure of the Greenland Ice Sheet. Science, 311(5673), 986990.

Rignot, E., J.E. Box, E. Burgess and E. Hanna. 2008. Mass balance of the Greenland ice sheet from 1958 to 2007. Geophys. Res. Lett., 35(20), L20502. (10.1029/2008GL035417.)

Schoof, C. 2010. Ice-sheet acceleration driven by melt supply variability. Nature, 468(7325), 803-806.

Shepherd, A., A. Hubbard, P. Nienow, M. McMillan and I. Joughin. 2009. Greenland ice sheet motion coupled with daily melting in late summer. Geophys. Res. Lett., 36(1), L01501. (10.1029/ 2008GL035758.)

Solomon, S. and 29 others. 2007. Technical summary. In Solomon, S. and 7 others, eds. Climate change 2007: the physical science basis. Contribution of Working Group I to the Fourth Assessment Report of the Intergovernmental Panel on Climate Change. Cambridge, etc., Cambridge University Press, 21-87.

Sundal, A.V., A. Shepherd, P. Nienow, E. Hanna, S. Palmer and P. Huybrechts. 2011. Melt-induced speed-up of Greenland ice sheet offset by efficient subglacial drainage. Nature, 469(7331), 521-524.

Taylor, J.R. 1997. An introduction to error analysis: the study of uncertainties in physical measurements. Second edition. Sausalito, CA, University Science Books.

Thomas, R.H. 1979. The dynamics of marine ice sheets. J. Glaciol., 24(90), 167-177.

Thomas, R.H. 2004. Force-perturbation analysis of recent thinning and acceleration of Jakobshavn Isbræ, Greenland. J. Glaciol. 50(168), 57-66.

Thomas, R.H., B.M. Csatho, S. Gogineni, K.C. Jezek and K. Kuivinen. 1998. Thickening of the western part of the Greenland ice sheet. J. Glaciol., 44(148), 653-658.

Thomas, R.H., W. Abdalati, E. Frederick, W.B. Krabill, S. Manizade and K. Steffen. 2003. Investigation of surface melting and dynamic thinning on Jakobshavn Isbræ, Greenland. J. Glaciol., 49(165), 231-239. 
Truffer, M. and K.A. Echelmeyer. 2003. Of isbræ and ice streams. Ann. Glaciol., 36, 66-72.

Van den Broeke, M. and 8 others. 2009. Partitioning recent Greenland mass loss. Science, 326(5955), 984-986.

Van der Veen, C.J. 1999. Fundamentals of glacier dynamics. Rotterdam, A.A. Balkema.

Van der Veen, C.J. and I.M. Whillans. 1989. Force budget: I. Theory and numerical methods. J. Glaciol., 35(119), 53-60.

Van der Veen, C.J., K.C. Jezek and L. Stearns. 2007. Shear measurements across the northern margin of Whillans Ice Stream. J. Glaciol., 53(180), 17-29.

Van de Wal, R.S.W. and 6 others. 2008. Large and rapid meltinduced velocity changes in the ablation zone of the Greenland Ice Sheet. Science, 321(5885), 111-113.
Velicogna, I. 2009. Increasing rates of ice mass loss from the Greenland and Antarctic ice sheets revealed by GRACE. Geophys. Res. Lett., 36(19), L19503. (10.1029/ 2009GL040222.)

Weertman, J. 1957. Deformation of floating ice shelves. J. Glaciol., 3(21), 38-42.

Weertman, J. 1974. Stability of the junction of an ice sheet and an ice shelf. J. Glaciol., 13(67), 3-11.

Whillans, I.M. and C.J. van der Veen. 1997. The role of lateral drag in the dynamics of Ice Stream B, Antarctica. J. Glaciol., 43(144), 231-237.

Whillans, I.M., Y.H. Chen, C.J. van der Veen and T.J. Hughes. 1989. Force budget: III. Application to three-dimensional flow of Byrd Glacier, Antarctica. J. Glaciol., 35(119), 68-80.

MS received 27 May 2010 and accepted in revised form 31 May 2011 